\title{
Os professores que tivemos e a formação da nossa identidade como docentes: um encontro com nossa memória.
}

Ana Luiza De Quadros ${ }^{1}$, Emerson Carvalho ${ }^{2}$, Flávia dos Santos Coelho ${ }^{2}$, Luciana Salviano ${ }^{2}$, Maria Fernanda P. A. Gomes ${ }^{2}$, Paula Cristina Mendonça ${ }^{2}$, Rosemary Karla Barbosa ${ }^{2}$.

1- professora - Depto de Química/ICEX/UFMG

2- aluno da licenciatura em Química DQ/ICEX/UFMG

\section{Resumo}

As poucas mudanças no modelo de transmissão/recepção, usado por muitos professores em suas salas de aula, levaram-nos a questionar a influência dos professores que tivemos na nossa formação profissional. Mesmo que os cursos de licenciatura enfatizem teorias mais modernas de ensino e aprendizagem, os professores acabam assumindo a posição de seus antigos professores. Observamos que a formação do professor não se da exclusivamente na licenciatura, mas durante toda a sua vida escolar e após a sua formação, na própria prática docente. As concepções sobre ensino e aprendizagem, sobre o papel da escola, do professor e do aluno, entre outras, podem ser questionadas através da retomada da história de vida de cada um dos professores.

Palavras-chave: história de vida, identidade docente, autoformação..

\section{Abstract}

The goal of this study is to question the influence of our former teachers in our professional career as teachers. Although the teaching courses at University emphasize the modern theories of theaching and learning, frequently the attitudes of the new teachers in classroom are mirrored in the behavior of their former teachers. The analyses showed that not only the theacher's training occurs at University but during all the school life and after the graduation. The discussion about the histories of lives should be used to question our conceptions of learning and teaching, the role of the school, the teachers and the students, towards changes in education.

Key-words: History of life, teacher identity, formation itself.

O Pequeno Príncipe, contra vontade, cativara a raposa, a pedido dela. Mas chegou a hora da despedida e a raposa disse: "Vou chorar". O Pequeno Príncipe retrucou: "Não é culpa minha. Eu não queria te cativar. Agora você vai chorar. Qual foi a vantagem?" Respondeu a raposa: "A vantagem? Os campos de trigo. Eu sou uma raposa. Como galinhas. O trigo me é indiferente. Mas você me cativou. Seu cabelo é louro. Os campos de trigo são dourados. Porque você me cativou sempre que o vento balançar as espigas douradas de trigo eu me lembrarei de você. E sorrirei..." (Saint-Exupéry) 
Nossa (pouca) experiência na área de educação tem mostrado a insatisfação de muitos professores com sua atividade profissional. São muito comuns afirmações como "o aluno não aprende", "não participa" ou "não está motivado para a aprendizagem". Acreditamos que a desmotivação dos alunos pode estar sendo reforçada pelas práticas pedagógicas usuais em sala de aula. Assim sendo, como professores ou futuros professores preocupa-nos o tipo de profissional que somos ou seremos e de que forma os professores que tivemos nos cativaram.

Ao focalizarmos a prática de um professor em sala de aula, vem-nos à memória os professores que já tivemos e a atuação de cada um deles. A alguns direcionamos fartos elogios; a outros, certas ressalvas. Mas percebemos que alguns deles parecem ter uma importância maior em nossas vidas. Provavelmente estes são os que nos cativaram. A questão que nos é posta refere-se à possibilidade de algum ou alguns deles terem influenciado a nossa vida no momento em que escolhemos o curso de graduação e no tipo de professor que seremos, já que podemos nos espelhar (ou não) em alguns deles. O efeito espelho tem sido muito citado em trabalhos sobre a atuação do professor.

Em algumas leituras referentes ao ensino de química, temos percebido uma forte preocupação com a concepção que se tem sobre "ensino" e sobre o papel do professor.

Em Maria Inês Rosa (2004, p.38) encontramos que as concepções de ensino são reflexos de outras que fazem parte do trabalho do professor. Segundo ela, ao considerarmos concepções de ensino, estaremos nos referindo ao que é ser professor, a quem é o sujeito que aprende (aluno), como se constitui o processo de ensino e aprendizagem e sobre a natureza do conteúdo que se ensina em sala de aula.

A concepção de ensino por transmissão vem sofrendo críticas consideráveis e, em contraposição a esta forma de ensino, surgiu uma preocupação com um ensino que partisse daquilo que o aluno já conhece. Esta nova postura tem influenciado a pesquisa em Educação nas últimas décadas, principalmente na área de Ciências. Isto tem provocado um aumento de interesse pelo processo de significação em salas de aula de Ciências, ao que concerne à busca de explicações sobre a formação e evolução de conceitos e do uso da linguagem.

Com isso, tem havido uma preocupação quanto ao entendimento individual dos estudantes sobre fenômenos específicos, direcionando o olhar para a forma como os significados e entendimentos de conceitos são desenvolvidos no contexto da sala de aula.

O foco dessa análise centra-se no processo de significação, criado na interação social e internalizado pelo indivíduo. Segundo Mortimer (2000), o significado antigo não é substituído pelo novo, mas cria-se um processo de negociação de significados num espaço de interação comunicativa, no qual há o encontro entre diferentes perspectivas culturais num processo de crescimento mutuo. As interações discursivas são, portanto, consideradas como constituintes do processo de construção de significados.

Os cursos de formação de professores, apesar de trabalharem essas novas concepções de ensino, nem sempre têm conseguido que os seus egressos atuem de maneira diferente daquela que seus professores atuavam.

Parece-nos que se criou um processo de continuismo na educação, no que se refere ao modelo de professor e às concepções que se tem sobre a prática de sala de aula, o qual precisa ser rompido. Larrosa (2001) tem trabalhado com as idéias de descontinuidade em educação. Segundo ele, essa descontinuidade seria representada por uma perturbação ao modelo de figura do professor já formada e já posta, de um imaginário social já construído. Então, quando um aluno ingressa num curso de licenciatura, ele pode ter uma concepção já construída do que é ser professor. O professor que o cativou pode, portanto, estar servindo de espelho.

Para romper com uma concepção já formada de professor, existem algumas propostas ou pesquisas que envolvem relatos biográficos ou autobiografia, histórias de vida, episódios de memória, entre outros. Cada um deles, com suas inúmeras peculiaridades, tenta fazer com que o indivíduo busque, em seu passado, as concepções que possui sobre ensino, aprendizagem, papel do professor, entre outras.

A descontinuidade, citada por Larrosa (2001) na formação de professores, pode estar abrindo espaço para o "porvir", ou seja, para um professor a ser formado sem uma identidade já pronta - a identidade do outro - mas propenso a 
construí-la, nos seus medos, nas suas dúvidas, na insegurança e na coragem de mostrar-se único, capaz e cheio de esperanças de constituir-se a partir de si mesmo.

Neste caso, formar o professor no "porvir" seria formá-lo com uma imagem a qual não se pode antecipar, nem projetar, nem prever, nem predizer. Como um professor que nasce e que não se constitui pela imagem do outro (tendo como outro o professor que já teve).

Na pesquisa de Catani, Bueno e Sousa (2000), encontramos o relato de um trabalho de autobiografia, envolvendo professores, alunos de pedagogia e alunos de licenciatura, sobre as marcas deixadas em suas vidas pelo ingresso na escola e pelos antigos mestres que tiveram. Segundo Catani et al (2000) "abordar a identidade implica, necessariamente, falar do eu, bem como das formas pelas quais o sujeito rememora suas experiências e entra em contato consigo mesmo" (p. 168). Afirmam, ainda, que "as memórias pessoalmente significantes são aquelas que carregam significados adquiridos em seus usos adaptativos, na maior parte das vezes, nas relações com os outros. Os outros são, desta forma, referências imprescindíveis das nossas lembranças" (p. 168-169).

A peculiaridade da formação do professor, por ter em seu mundo de trabalho o mesmo "espaço" no qual foi formado, ou seja, a sala de aula, favorece a que ele assuma, depois de formado, não só a posição física de seus professores, mas também a postura, atitudes, formas de ensinar etc, fazendo um efeito "espelho". Em Catani et al (2000) encontramos que "Ao atuarem como espelhos, as lembranças são por nós apropriadas, tornando-se elementos integrantes e inseparáveis de nossas memórias" (p. 169).

Cavaco (1995) ao referir-se a história de vida de professores, cita que a importância do passado está vinculada à "necessidade de procurar o fio de vida para valorizar o presente e reinventar o futuro". (p. 184)

É com esta preocupação que "visitamos" nossas próprias memórias e as memórias de uma amostra de alunos da Licenciatura em Química. Pretendíamos, antes de tudo, responder a algumas questões que nos fizemos: Por que alguns alunos, apesar de discutirem teorias de ensino e aprendizagem, acabam, na maioria das vezes, usando o modelo de transmissão/recepção? Essa prática de sala de aula é influenciada pela prática dos professores que tiveram? A graduação é decisiva para a formação da identidade de professor?

Diante da possibilidade de influência do professor em nossa vida, e do fato de termos na memória a prática de algum professor do passado, despertou-nos a curiosidade de saber se os alunos da graduação têm, na memória, algum professor que tenham considerado importante e quais as características deste professor.

Assim sendo, resolvemos dirigir o nosso olhar aos alunos da Licenciatura em Química da UFMG, e tentar remexer as suas memórias sobre professores do passado, que tenham tido alguma influência mais direta em suas vidas.

Com base no que chamamos de episódios de memória, tentamos explicitar algumas relações desses indivíduos com os seus professores e o significado dessas relações na formação da identidade profissional. Usamos "episódios de memória" por que trabalhamos com entrevistas e, assim, conseguimos identificar o que estava mais presente em suas memórias, como episódios de sua vida escolar. Usamos uma amostra de, aproximadamente, $60 \%$ dos alunos da Licenciatura em Química da UFMG, dos dois últimos semestres, de forma que os professores da graduação também pudessem ser citados.

\section{Encontrando nossa memória}

Entrevistamos 36 alunos dos dois últimos períodos do curso de licenciatura em química da UFMG, que representam em torno de $60 \%$ do total de alunos dos dois últimos semestres. Do total de entrevistados 34 afirmaram lembrar de algum professor de maneira especial.

Os professores lembrados pelos entrevistados atuaram na educação básica e na educação superior, como mostrado no quadro 1 . 
Quadro 1. Número de alunos e nível de atuação do professor lembrado.

\begin{tabular}{|c|c|}
\hline Nível de atuação & Total de alunos \\
\hline Educação Básica (ensino fundamental) & 8 \\
\hline Educação Básica (ensino médio) & 16 \\
\hline Pré-vestibular & 5 \\
\hline Educação Superior & 5 \\
\hline Total & 34 \\
\hline
\end{tabular}

Nossa intenção inicial era analisar a influência do professor na escolha do curso de graduação dos entrevistados. Portanto, para esta análise, não incluímos os professores que atuavam no ensino superior.

Como os entrevistados são alunos do curso de química na universidade, buscamos saber quais dos professores lembrados atuavam na disciplina de química. Incluímos mais dois professores de Ciências, pois os entrevistados, ao citarem professores de Ciências, justificaram gostar das experiências que eram desenvolvidas na disciplina, o que, no nosso entender, denota uma relação direta com a opção pela Química.

Então, com esta inclusão, tivemos os seguintes dados:

Quadro 2. Professores lembrados pertencentes à área de Química

\begin{tabular}{|c|c|}
\hline Disciplina & $\mathrm{N}^{\mathbf{o}}$ de professores lembrados \\
\hline Química do Ensino Médio & 10 \\
\hline Química do Pré-vestibular & 02 \\
\hline Ciências & 02 \\
\hline Total & 14 \\
\hline
\end{tabular}

Percebemos que os professores lembrados podem ter influenciado na escolha do curso superior pelo fato de $48 \%$ das memórias remeterem a professores das disciplinas anteriormente mencionadas. Alguns entrevistados declararam explicitamente a influência de um professor na escolha do curso de Química na graduação, como pode ser visto na passagem abaixo:

"A matéria foi muito gostosa de aprender. Lembro de tudo que ela [a professora] falava e escolhi química por causa dela. Ela me incentivou muito e ficou toda feliz quando disse que ia fazer química. Emprestou-me um monte de livros: Vera Novaes, Tito e Canto, muito bom!” (grifo nosso)

Se a amostra de alunos entrevistados for representativa, podemos afirmar que aproximadamente metade dos alunos é influenciada pelos professores na escolha do curso superior. Caso consideremos que a escolha pelo curso de química pode ter sido influenciada por professores da área de ciências da natureza, matemática e suas tecnologias, então esse número sobe para aproximadamente $79 \%$.

Outra análise que pretendíamos fazer se refere ao interesse pela disciplina ter sido desenvolvido pelo fato de gostar do professor. Alguns dos entrevistados não fizeram referência ao conteúdo ministrado pelo professor de sua memória. Entre os 22 que fizeram referência, 12 deles afirmaram que passaram a gostar da disciplina que o professor lembrado lecionava, a partir das aulas desse professor.

Para a análise das referências de memória, classificamos as características descritas sobre o professor da memória em três categorias, a saber: afetiva, pedagógica e de conhecimento.

$\mathrm{Na}$ categoria afetiva foram enquadradas aquelas referências que valorizavam a relação professor-aluno. Incluíram-se aí, então, os itens que se referem à amizade, companheirismo, respeito, entre outras. Professores desta categoria foram descritos como atenciosos, compreensivos, humanos, independente do domínio de sua disciplina. Também estão incluídos os professores que incentivam e orientam os alunos para a vida. 
Como pedagógicas foram incluídas as características relacionadas ao ensino e a aprendizagem. Nesta categoria foram colocados os itens que se referem à metodologia e/ou à forma de explicar o conteúdo, o planejamento de ações, o aproveitamento do tempo, materiais usados, a discussão de temas atuais, entre outros.

Entre as características que classificamos como de conhecimento estão aquelas que se referem ao domínio do conteúdo e ao saber do professor.

O quadro 3 apresenta a distribuição das memórias de acordo com as categorias em que foram classificadas.

Quadro 3. Referências das memórias dos entrevistados.

\begin{tabular}{|c|c|}
\hline Referência da memória & $\begin{array}{l}\text { Número } \\
\text { memórias }\end{array}$ \\
\hline Afetiva & 20 \\
\hline Pedagógica & 23 \\
\hline Conhecimento & 5 \\
\hline
\end{tabular}

O maior número de características citadas sobre um professor que lembre de forma especial está na categoria que classificamos como pedagógica.

Parece que foi nestas características que os entrevistados tiveram uma percepção de aprendizagem. Algumas das falas deixam isto bastante claro, como por exemplo:.

“Eu gostava dele muito, pois ele saía do padrão de qualquer outro tipo de professor que eu tinha, porque ele era um professor dinâmico, no sentido de ilustrar bastante a matéria, isso fazia com que a gente guardasse mais os conceitos que ele passava.”

"Ela era muito boa, era muito inteligente e cobrava muito dos alunos e tinha um jeito muito bom de explicar, que facilitava o entendimento."

"...com um outro tipo de metodologia e de trabalhar com a matéria, eu consegui aprender bem com esse professor."

Nestes entrevistados há uma evidente memória de aulas diferentes, com novas formas de ensinar, que prendem a atenção do aluno e que, segundo eles, leva a uma aprendizagem.

Tínhamos, inicialmente, como hipótese, que o conhecimento do professor fosse fator importante para que este permanecesse na memória dos alunos. Observando o resultado das entrevistas, percebemos o contrário. O fator afetivo mostrou-se bem mais importante que o saber.

"Ele marcou a minha vida não só por ter sido um excelente professor de química, mas também por ter sido um grande amigo para mim."

"E essas brincadeiras incentivavam mais a gente, fazendo com que a gente tivesse uma aproximação maior do professor..."

"...o modo como ele tratava os alunos, com igualdade..."

O grande número de comentários destacando a relação professor versus aluno, independente do conteúdo ministrado, leva-nos a afirmar que, mesmo estando em sala de aula, não é só conhecimento que o aluno busca. Ele almeja um ambiente agradável, com diálogo, com companheirismo, com respeito. Ele almeja uma relação de confiança em sala de aula. Esses entrevistados demonstraram que, entre todos os professores que já tiveram, os que estão presentes em suas memórias desenvolveram uma relação que ia além do conteúdo.

Buscamos nos professores do curso superior as características dos mesmos, que fizeram com que eles permanecessem na memória dos nossos entrevistados. Também lá o fator conhecimento não foi o mais citado. 
Outra análise que pretendíamos fazer referia-se à possibilidade das características dos professores lembrados influenciarem no tipo de professor que nossos entrevistados são/serão. Entre os entrevistados 17 já são professores, 07 já atuaram em sala de aula porém estão fora das salas de aula hoje e outros 10 nunca atuaram como professor.

De maneira geral, os entrevistados citaram características que incorporaram ou que pretendem incorporar de seus professores de memória, sendo elas as mais variadas possíveis. Destacamos, abaixo, aquelas que mais apareceram:

Quadro 4. Principais características incorporadas ou desejáveis

\begin{tabular}{|c|c|c|c|}
\hline Característica & $\begin{array}{c}\text { Não Professores } \\
(17)\end{array}$ & $\begin{array}{c}\text { Professores } \\
(17)\end{array}$ & $\begin{array}{c}\text { Total } \\
(34)\end{array}$ \\
\hline forma de explicar/metodologia & 02 & 05 & 07 \\
\hline amizade/companheirismo & 02 & 03 & 05 \\
\hline exigência & 01 & 02 & 03 \\
\hline bom-humor/brincalhão & 02 & 02 & 04 \\
\hline diálogo constante & - & 03 & 03 \\
\hline atencioso & 02 & 02 & 04 \\
\hline contextualiza o conhecimento & 01 & 02 & 03 \\
\hline Nenhuma & 03 & - & 03 \\
\hline
\end{tabular}

Além destas características, várias outras foram citadas, mas com um número de vezes não superior a duas. Entre elas estão a manutenção da disciplina, respeito, pontualidade, seriedade, jogo de cintura, humildade, o saber fazer relações com outras áreas do conhecimento, a capacidade de mostrar a importância da disciplina, incentivo, igualdade no tratamento dos alunos e outras. Em três entrevistas, os entrevistados afirmaram incorporar características do professor de memória porém, não foram específicos em citar quais seriam estas características. Nas 3 entrevistas que afirmaram não incorporar qualquer características do professor lembrado, os professores de memória foram considerados ruins e, por este motivo, permanecem na memória dos entrevistados. Para estes, nenhuma característica será incorporada, segundo eles próprios.

Fizemos um levantamento superficial tentando evidenciar se as características citadas como incorporadas ou de incorporação desejável são trabalhadas dentro da Licenciatura em Química da UFMG. Este levantamento foi feito entre os próprios alunos pesquisadores. Segundo eles os itens metodologia/forma de explicar, manutenção da disciplina, contextualização do conhecimento, organização, diálogo, importância da disciplina, incentivo e igualdade no tratamento dos alunos estão presentes, de alguma forma, em disciplinas por eles cursadas.

\section{As imagens formadas e o processo identitário}

De acordo com os resultados obtidos a partir das entrevistas, podemos perceber que a formação do professor não se dá apenas durante o curso de licenciatura. As características lembradas pelos entrevistados que já atuam como professor são um pouco diferentes daquelas citadas por aqueles que nunca atuaram como docente. Isso evidencia não só que a formação do professor se dá também com sua prática diária em sala de aula, mas que a memória de seus antigos professores também exerce forte influência. E, principalmente, que esta influência é mais facilmente percebida durante sua prática de sala de aula.

A partir dos episódios de memória, podemos perceber nítidas relações entre as experiências escolares e a formação da identidade do professor. Mesmo tendo claro que a fantasia e/ou idealização permeiam narrativas quando elas envolvem lembranças, memórias e recordações, podemos considerar que a maneira como o passado é reconstruído pode representar como o entrevistado pretende que seja a sua vida (postura). Concordamos com Catani et alii, quando afirmam que 
as experiências vividas não desaparecem com a história do sujeito e que cumprem um papel crucial na formação docente, mediante as imagens que se vão formando sobre o professor como profissional.

Também pudemos perceber que os dados por nós obtidos abrem possibilidades de pesquisas futuras, uma vez que muitas falas dos entrevistados abrem espaço ou para questionar e aprofundar a análise sobre o papel do professor em confronto com aquilo que é estudado na licenciatura, ou para pesquisar um grupo mais restrito de professores, em suas práticas de sala de aula, para analisar as suas ações em comparação com as do professor que descreveram.

Não podemos deixar de nos referir à licenciatura. $\mathrm{O}$ fato de que, mesmo estudando teorias de aprendizagem, o egresso da licenciatura assumir, muitas vezes, uma postura de transmissão de conceitos pode estar acontecendo, também, por que ele tem uma concepção de professor já formada durante toda a sua vida escolar e, uma vez que, na sua escolarização, esteve presente a transmissão/recepção, a imagem de professor como transmissor de conhecimento está presente de forma muito significativa. Sabendo que há um "modelo" de professor já posto, uma das possibilidades de "perturbar" esse modelo seria trabalhar a memória de cada um, para que, através de um processo de auto formação, o indivíduo identifique as concepções que tem sobre professor, ensino, aprendizagem, escola, etc e como elas foram construídas. Pensamos que essas concepções devam ser percebidas e questionadas dentro das licenciaturas, de forma que evoluam e que o aluno perceba que, dentro de uma nova realidade, um novo modelo de professor se faz necessário.

A racionalidade técnica em que se tem centrado os curso de formação de professores desprivilegia outras dimensões importantes e, entre elas, a "convinialidade" dos alunos com seus professores, durante toda a vida escolar. Segundo Nóvoa (1992) a virada na formação de professores teve um marco importante: o livro "O professor é uma pessoa" de Ada Abraham, lançado em 1984, em Paris. A partir daí, segundo ele "a literatura foi invadida por obras e estudos sobre a vida do professores" (p. 15).

A identidade do professor, segundo Nóvoa (1992) "é um lugar de lutas e de conflitos, é um lugar de construção de maneiras de ser e de estar na profissão" (p. 16). A construção dessa identidade profissional é um processo longo e complexo. Necessita de tempo, portanto. Necessita de acomodar inovações, assimilar mudanças, re-pensar a prática pedagógica num processo de auto-consciência sobre o que faz, como faz e por que faz em sala de aula, com os saberes (seus e de seus alunos)

Acreditamos que a pesquisa ora desenvolvida serviu não só para pensarmos sobre a formação dos nossos entrevistados enquanto professores, mas, principalmente, para refletirmos, discutirmos e analisarmos a nossa própria formação, não só profissional, como também pessoal. Percebemos que cada um de nós carrega uma imagem ou modelo de professor que é formado durante todo o período de escolarização e que, com o acréscimo de outros saberes obtidos na licenciatura ou incorporados pela própria prática - constroem a nossa identidade como profissionais, fazendo-nos assim professores.

A formação do professor poderia, quem sabe, considerar de maneira mais relevante, o conhecimento sobre si próprio e não enfatizar tanto o conhecimento da disciplina que ensina. Resta saber como isso poderia ser feito, do ponto de vista prático, sem que se torne apenas "modismo" ou que a formação seja pouco consistente.

Parece evidente, para nós, que somos cativados por professores e que acabamos por assumir a postura de alguns destes professores que nos cativaram. Apesar de se discutir teorias de aprendizagem, ao olharmos para nossos alunos, lembraremos do professor que tivemos e da forma como ele agiria em determinadas situações. Assim como o trigo lembrará à raposa o cabelo do Pequeno Príncipe, também nosso trabalho em sala de aula lembrará o trabalho dos professores que tivemos. 


\section{Referências Bibliográficas}

CATANI, Denice Barbara, BUENO, Belmira e SOUSA, Cyntia. O amor dos começos: por uma história das relações com a escola. Cadernos de Pesquisa. No 111, p. 151 - 171, dez. 2000.

CAVACO, Maria Helena. Ofício de Professor: o tempo e as mudanças. In: Nóvoa, Antônio (org.). Profissão Professor. Portugal : Porto Editora, 1995.

LARROSA, Jorge. Dar a palavra: Notas para uma dialógica da transmissão. In: Larrosa, Jorge. Habitantes de Babel. (trad. de Semíramis Gorini da Veiga) Belo Horizonte : Autêntica, 2001.

MORTIMER, Eduardo Fleury. Linguagem e Formação de conceitos em Ensino de Ciências. Belo Horizonte : UFMG, 2000.

NOVOA, Antonio. Os professores e as Histórias da sua vida. In: NÓVOA. António (org.) Vidas de Professores. Portugal : Porto Editora, 1992.

ROSA, Maria Inês Petrucci. Investigação e Ensino: articulações e possibilidades na formação de professores de Ciências. Ijuí : UNIJUI, 2004.

SAINT-EXUPÉRY, Antoine. O pequeno Príncipe. $48^{\circ}$ ed. Rio de Janeiro: Agir, 2004

DATA DE RECEBIMENTO: 18/02/05

DATA DE APROVAÇÃO: 25/08/05 